\title{
Espacio público y tejido social en Tibás: Diagnóstico participativo de las relaciones institucionales (2017-2018)
}

\author{
Natalia Caro Bernal
}

Artículo

Afiliación: Independiente, San José, Costa Rica.

E-mail: naticarobe@gmail.com

Recibido: 11 de diciembre del 2018

Aceptado: 12 de abril del 2019

\section{Natalia Caro Bernal}

Bachiller y Licenciada en Sociología por la Universidad de Costa Rica. Becaria del Instituto de Investigaciones Sociales de la Universidad de Costa Rica.

\section{Resumen}

El artículo tiene como objetivo general analizar los vínculos entre instituciones formales sobre el uso y la participación en los parques públicos de Tibás para la planificación de líneas estratégicas de acción sobre la gestión de proyectos de arte, cultura, educación y recreación. En el artículo se analizan las relaciones y vinculaciones que tienen los individuos en los grupos sociales que participan de manera activa y en donde construyen sus subjetividades para posteriormente, en el proyecto de investigación, analizar la información con la participación comunal en cada uno de los cinco distritos.

Palabras Clave: apropiación; espacio público; relaciones sociales; uso; vínculos.

Public Space and Social Networks in Tibas: Participatory Analysis of Institutional Networks (2017-2018)

\begin{abstract}
:
The article has the main objective of analyzing the formal institutional links of the usage and participation of the public parks in Tibás, planning strategic lines of action of project management in art, culture, education, and recreation. In the article, the author analyzes the relationships and links of people in the groups they constantly participate in and build their own subjectivities. Then, in the project of graduation, the author analyzes with the communal participation of the five districts of the canton the information of the institutions.
\end{abstract}

Keywords: appropriation; links; public parks; social networks; uses. 


\section{Introducción}

$\square$

ste artículo se elaboró como parte de una investigación financiada por el Instituto de Investigaciones Sociales de la Universidad de Costa Rica gracias al programa de becas de investigación. En este, se evidencia que los espacios públicos de recreación requieren una adecuada gestión y planificación por parte de las comunidades y gobiernos locales. Sin embargo, muchas veces no se toman en cuenta cuáles son las necesidades y gustos de la población en sus tiempos de ocio y recreación a la hora de realizar las mejoras correspondientes. Según la Carta Mundial por el Derecho a la Ciudad del Foro Mundial de las Américas (2004), se indica la importancia de estos espacios, ya que son fundamentales para el desarrollo personal y social. Para efectos de este artículo, se hace énfasis en los parques públicos de Tibás.

En el cantón se evidencia una falta de uso y participación comunal en los parques públicos. Esta es una problemática persistente según información suministrada por la alcaldía municipal, ya que es un cantón mayoritariamente industrial y comercial con altos niveles de inseguridad, ocupando el puesto número 47 de los 81 cantones según el Índice de Desarrollo humano con el de Seguridad Ciudadana Cantonal (2009). Según el Diagnóstico de Niñez y Adolescencia del Patronato Nacional de Infancia (PANI) 2014, los menores de edad manifestaron que a pesar de que en el cantón hay muchos espacios púbicos, estos se encuentran en su mayoría en mal estado y son poco utilizados por la población.

Figura 1. Foto tomada en el taller institucional del 27 de julio del 2018.

Fuente: elaboración propia.



Este articulo brinda un insumo a la Municipalidad de Tibás, instituciones y otros sectores de la comunidad sobre líneas estratégicas de acción para el mejoramiento de espacios públicos. Esto cobra importancia en diversas instituciones como las asociaciones de desarrollo, centros de salud, centros educativos y las diferentes organizaciones en donde se busca retomar las relaciones y vínculos entre grupos organizados sobre la participación en parques públicos durante el año 2017 y 2018.

La metodología se basa en un diagnóstico participativo que cumple el formato presentado por Rocio Loria, profesora de antropología de la Universidad de Costa Rica, en técnicas para la recolección de datos y el diseño de estrategias participativas focalizadas en cada uno de los cinco distritos según los sectores sociales de salud, educación, comunidad y gobierno local. La recolección de información se realiza mediante 11 entrevistas semiestructuradas para el análisis de las redes existentes entre organizaciones tanto públicas como privadas, para promover la participación comunal y un taller institucional para la planificación de proyectos. Un aspecto fundamental para la gestión y planificación de actividades culturales, educativas y recreativas es realizarlas en conjunto con diferentes organizaciones para que motiven a la población a participar en actividades en parques públicos, para el desarrollo personal y social de las personas de la comunidad.

En el cantón de Tibás se encuentran identificados 132 espacios públicos según datos municipales ${ }^{1}$ con diferentes usos para la población: plazas deportivas, parques 
Figura 2. Foto tomada en el taller institucional del 27 de julio del 2018.

Fuente: elaboración propia infantiles, estadios y zonas verdes, de las cuales un $40 \%$ han tenido cambios en la infraestructura y uso durante el tiempo. Muchas de las mejoras que se han realizado en algunos de estos espacios serían más efectivas si se incorpora la participación comunal para la toma de decisiones y el desarrollo de actividades culturales, educativas y recreativas adecuadas para la población. En los espacios que no han tenido mejoras de infraestructura, es necesario desarrollar estrategias de intervención para mejorarlos y potenciar la participación comunitaria de los mismos.

El objetivo general del artículo es analizar los vínculos entre organizaciones comunales públicas y privadas sobre el uso y la participación en los parques públicos de Tibás para la planificación de estrategias con las personas de la comunidad sobre el uso de los espacios públicos para arte, cultura, educación y recreación. Esto mediante un diagnóstico participativo que involucre a las personas de distintas instituciones en donde se definan líneas estratégicas de acción orientadas a la apropiación comunal de los parques públicos. Se hará referencia al desarrollo del marco conceptual, el contexto de la investigación, la metodología, los resultados y conclusiones según la teoría del análisis de redes sociales.



\section{Referente teórico}

A continuación se presentarán las nociones en cuanto a lugar, espacio y territorio para definir en la ciudad, en este caso en el cantón Tibás. El lugar se define según Marta Rizo como "elemento aglutinante de la colectividad y como símbolo de su permanencia en el tiempo" (Rizo, 2006, p. 9), donde se visualiza un lugar espacial con límites establecidos que se definen por las prácticas sociales de las personas participantes. En este caso, los parques públicos como lugares de socialización y aprendizaje de diferentes expresiones culturales.

El espacio se convierte entonces en un lugar mediante las actividades realizadas por parte de las personas que lo transforman y le dan significados al espacio que habitan; por lo tanto, si se visualizan lugares con una fuerte identidad cultural que ayude a conglomerar a la colectividad, se lograría una mayor identidad social que permita la apropiación comunal de un territorio y logre la identidad del lugar. Marta Rizo cita en su texto a Pol y explica que la organización simbólica del espacio, la cual se convierte en un lugar por la interacción transformadora de las personas, es lo que se llama 'apropiación del espacio' (2006).

La sociología urbana comprende el barrio como el espacio donde se articulan las diversas expresiones sociales ya que es integrador, tiene un referente espacial, es generador de identidad y es un espacio articulador tanto entre lo privado e individual y las redes sociales de apoyo. Por lo tanto, se considera necesario abordar la teoría del análisis de redes para comprender de manera más amplia el cómo la participación activa en grupos comunales permite enriquecer la investigación para la comprensión de la construcción constante de subjetividades al rededor del tema del espacio público para el arte, la cultura, la educación y la recreación. 
Teoría del análisis de Redes Sociales

Se realiza el análisis de redes sociales desde la visión relacional de esta teoría planteada por Barry Wellman (1991), donde se hace énfasis en la estructura y el análisis de redes con la información que proporcionan los individuos de las diferentes instituciones. Estos son interpretados según las construcciones estructurales sobre las actividades que realizan y las fuerzas y relaciones que los vinculan y unen con otros. Para el autor, son las relaciones las que influyen en los comportamientos de los miembros dentro de las redes. El método de categorías de descripción y análisis es reemplazado por métodos relacionales donde la estructura se ve como una red de grupos y conexiones visualizadas mediante gráficos, que presentan las medidas de centralidad según el número de relaciones con otras instituciones, el número de referencia para la planificación de otras instituciones, las medidas de relación y las medidas de centralidad entre instituciones.

\section{Encuadre conceptual Teoría del Análisis de Redes Sociales}

La teoría del Análisis de Redes Sociales de Barry Wellman plantea delimitar el conjunto de actores, individuos, organizaciones, comunidades y sociedades vinculados unos a otros a través de relaciones sociales. Para realizar el análisis, se deben estudiar las características de estos lazos y vínculos para interpretar los comportamientos sociales de las personas. Para definir las categorías de análisis se hace referencia a los conceptos planteados por Wasserman y Faust (1994, p. 17-20). ${ }^{2}$

Los actores sociales son entidades sujetas a vínculos de redes sociales como individuos, empresas, unidades colectivas sociales, departamentos, agencias de servicio público, etc. Estos actores sociales tienen una gran influencia en la construcción de las subjetividades de las personas, ya que son en estos espacios donde se dan gran parte de las relaciones sociales y los vínculos entre organizaciones. El concepto de lazos relacionales / conexión relacional se entiende como los vínculos entre actores mediante el análisis de las redes sociales (personales, amistad, respeto, consejo, trabajo, dinero, etc.). Este concepto se analiza mediante entrevistas semiestructuradas a diferentes organizaciones para conocer las otras instancias con las cuales tiene relaciones y vínculos para promover sus proyectos y programas.

La diada es definida como la relación específica entre dos actores que trabajan inherentemente unidos por un lazo relacional. Este concepto es importante para conocer cuál es el grado de vinculación entre organizaciones e identificar posibles nuevas relaciones que fortalezcan los procesos. La triada se entiende como el conjunto de tres actores y sus relaciones, el análisis del balance y las propiedades entre sí. El concepto de subgrupo es analizado como una extensión de los conceptos anteriores por subconjuntos de actores y los lazos. Los grupos son las redes sociales que tienen capacidad de organización y de tener lazos entre ellos. Los tipos de relación pueden ser unidireccionales (no recíprocas) y bidireccionales (recíprocas)

Estos aspectos son fundamentales para estudiar las relaciones y los vínculos existentes entre los diferentes grupos para realizar un estudio que identifique relacionalmente las conexiones directas e indirectas que existen entre las unidades de una red y como los grupos en los que participamos activamente influyen en las representaciones sociales que tenemos sobre determinado espacio o lugar. Esta investigación está focalizada al análisis micro, poniendo énfasis en sociogramas de pares ordenados, diadas y triadas que evidencien las relaciones entre los diferentes grupos y el grado de vinculaciones que tienen directa 0 indirectamente en los procesos de convocatoria, ejecución y planificación de actividades o programas en los parques públicos de las instituciones interesadas en participar del proyecto. 
Figura 3. Foto tomada en el taller institucional del 27 de julio del 2018.

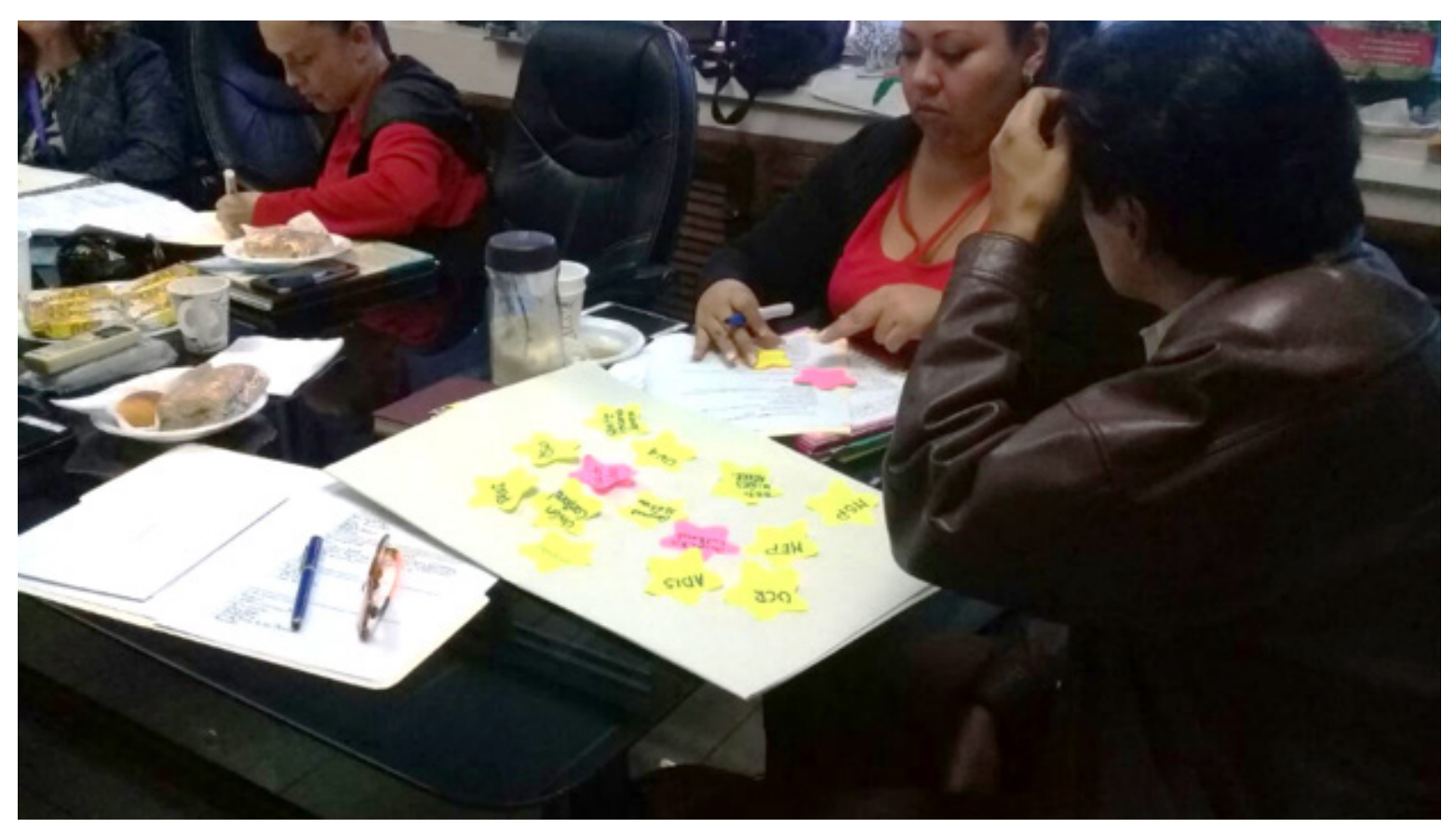

Marco normativo

En el siguiente apartado, se presenta una revisión de las leyes estipuladas en Costa Rica en torno al espacio público o áreas verdes desde la Política Nacional de Ordenamiento Territorial 2012-2040 por el Ministerio de Vivienda y Asentamientos Urbanos, la Ley de Planificación Urbana, el Código de la Niñez y Adolescencia y el Plan Regulador de Tibás 2016-2020.

En la Política Nacional de Ordenamiento Territorial 2012-2040 por el Ministerio de Vivienda y Asentamientos Urbanos publicada en el 2012, el apartado "Paisaje, áreas verdes, recreativas y espacios públicos" hace referencia a que se debe garantizar un equilibrio entre el espacio construido para vivienda y el medio natural. Textualmente presenta tres aspectos fundamentales: la dimensión física (el paisaje es el territorio), la dimensión subjetiva y cultural (la población atribuye valores subjetivos al territorio) y, finalmente, la dimensión temporal/causal (el paisaje como resultado de la interacción entre el ser humano y la naturaleza).

En el lineamiento 7, se busca promover la identificación, el estudio, la recuperación, protección y conservación del paisaje urbano, rural y natural como espacios para generar salud y bienestar con el fin de garantizar la participación de hombres y mujeres en dicho proceso. Por último, el lineamiento 8 incentiva la construcción de más área verde, espacio público y recreativo en los asentamientos humanos hasta alcanzar la medida de $10 \mathrm{~m}^{2}$ por habitante para que sea privilegio para toda la población. Según información suministrada por el geógrafo municipal Alberto Duran en Tibás, esta medida es de $4,96 \mathrm{~m}^{2}$ por habitante, por lo tanto, podemos confirmar que no se cumple este lineamiento de la Política Nacional de Ordenamiento Territorial 2012-2040.

La Ley de Planificación Urbana en el artículo 16 estipula:

De acuerdo con los objetivos que definan los propios y diversos organismos de gobierno y administración del Estado, el plan regulador local contendrá los siguientes elementos, sin tener que limitarse a ellos: e) Los servicios comunales, para indicar ubicación y tamaño de las áreas requeridas para escuelas, colegios, parques, campos de juego, unidades sanitarias, hospitales, bibliotecas, museos, mercados públicos y cualquier otro similar. (1968)

Por lo tanto, el Plan Regulador de Tibás debe contener los aspectos mencionados anteriormente para cumplir con la legislación vigente en cuanto a los terrenos destinados para zonas verdes para que no se excedan en la planificación de construcciones tanto de viviendas como de locales e industrias, como ha sucedido en Costa Rica y muchos países del mundo.

Según el artículo 40 de la Ley de Planificación Urbana, se deberá ceder a uso público entre un cinco por ciento a un veinte por ciento, según el tamaño promedio de los lotes previstos para construcción, el uso que se pretenda dar al terreno y las normas al respecto. Seguidamente, la ley estipula que la suma de los terrenos que deben cederse para vías públicas, parques y facilidades comunales no debe exceder de un cuarenta y cinco por ciento de la superficie total del terreno a fraccionar o urbanizar.

Un aspecto fundamental que se menciona en el artículo 44 de la Ley de Planificación 
Urbana es el dominio municipal de estas áreas, ya que debe estar registrado en el mapa oficial del cantón y en el registro de propiedad para poder hacer del terreno un espacio público abierto al uso de las personas en general y así poder intervenir con programas y proyectos con fondos públicos. Este debe estar registrado a nombre de la municipalidad para no tener problemas legales de tenencia del terreno a la hora de incidir en estos espacios.

El Código de la Niñez y Adolescencia de 1997 en el artículo 75 estipula el derecho a infraestructura recreativa y cultural. Además, se indica que el Ministerio de Cultura, Juventud y Deporte y las municipalidades deben establecer las políticas respectivas para que las personas menores de edad cuenten con espacios adecuados a nivel nacional para ejercer los derechos recreativos y culturales. Es fundamental contar con espacios que cumplan los derechos de todas las personas sin distinción de edad, sexo, preferencia sexual, etnia, etc.

Según el Plan Regulador de Tibás 2016-2020, un tema a mejorar en calidad ambiental es la recuperación y mejora de zonas verdes (parques, jardines y juegos infantiles y proyectos para reforestar en zonas estratégicas para la recuperación de los recursos naturales). En el informe del mapeo de espacios públicos para recreación y deporte, se presenta que en Tibás hay un aproximado de 7 zonas deportivas, 80 áreas destinadas a la recreación con parques infantiles, zonas de reunión y se menciona que existen zonas invadidas o en estado de abandono. Esto demuestra que la municipalidad realizó un esfuerzo por estudiar el estado de las zonas verdes, sin embargo, en este plan no se presentan líneas de acción o proyectos concretos para la mejora sustantiva tanto en infraestructura como en gestión y planificación de proyectos comunales.

Figura 4. Mapa del cantón Tibás Fuente: Dirección general de gestión urbana departamento geografía a cargo de Lic. Alberto Durán.

\section{Descripción del entorno donde se realiza el diagnóstico participativo}

El cantón de Tibás pertenece a la provincia de San José, Costa Rica. Tiene una población de 64,842 habitantes según datos del último censo del Instituto Nacional de Estadística y Censo (INEC) del 2011. Está conformado por cuatro distritos: San Juan (21,745 personas) Cinco Esquinas (5,925 personas) Anselmo Llorente (9,986 personas) León

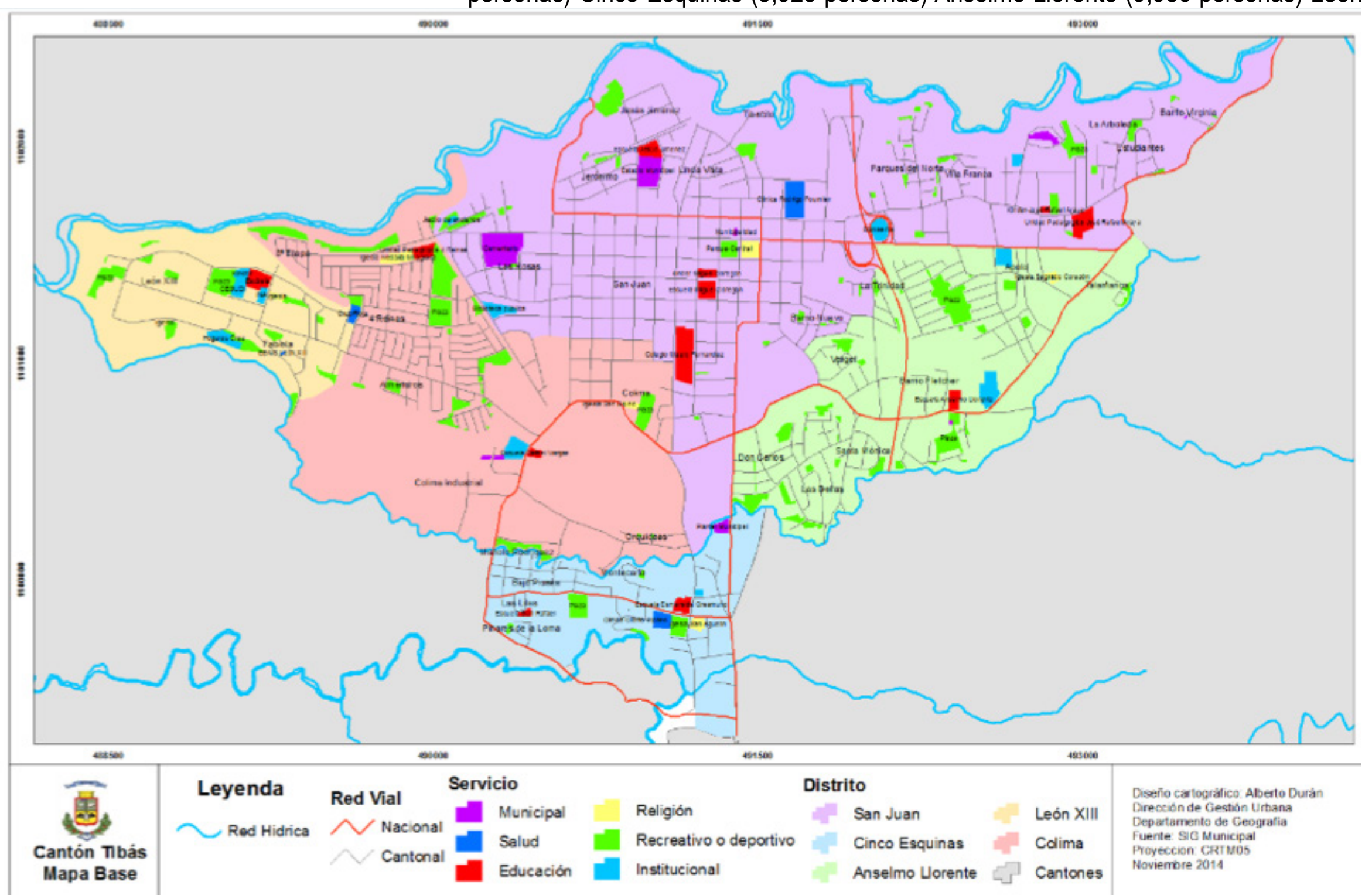


XIII (13,661 personas) y Colima (13,525 personas). Los últimos estudios realizados en conjunto ${ }^{3}$ con la municipalidad y el Patronato Nacional de la Infancia concluyen que uno de los principales problemas es la falta de actividades y mejoramiento de espacios públicos para la recreación y deporte que promuevan la apropiación comunal en el cantón.

El contexto del cantón de Tibás es en su mayoría de índole industrial y comercial según información suministrada por la municipalidad, ya que no cuenta con patrimonios ni infraestructura cultural, requiriendo una intervención para el reconocimiento cultural y apropiación comunal de los espacios. Cuenta con muchas áreas verdes y parques públicos en los que se puede trabajar para aumentar la participación ciudadana. En los mapeos de infraestructura de parques, se evidenció la falta de apropiación de estos espacios por parte de las comunidades. Esto denota una subutilización de recursos en una comunidad en donde se requiere de espacios públicos en los que se promuevan actividades culturales, educativas y recreativas, que contribuyan a la construcción del tejido social, a disminuir los índices de violencia y a dotar de espacios seguros para la interacción social y el desarrollo personal.

En el cantón de Tibás se encuentran muchas instituciones que velan por el cumplimiento de los derechos de las personas, por ejemplo el Patronato Nacional de la Infancia, los Scouts, la Municipalidad de Tibás, las escuelas públicas, las Asociaciones de Desarrollo, los tres Centros de Salud (Clorito Picado, ASEMECO y COOPESAIN), entre otros. En Tibás se ha conformado una junta de protección de la niñez y adolescencia coordinada por el Patronato Nacional de la Infancia, donde participan diferentes personas que procuran y promueven el cumplimiento de los derechos de los niños, niñas y adolescentes. De igual manera se ha conformado una red llamada RCAFIS, coordinada por el Ministerio de Salud que trabaja para propiciar espacios de recreación. Estos fueron puntos estratégicos de convocatoria y gestión de proyectos. Este artículo tiene como fin presentar un informe, para que, en conjunto con la municipalidad y las organizaciones civiles, se pueda realizar mejoras notables en estos espacios para la promoción de su uso en arte, cultura, educación y recreación.

\section{Estrategia Metodológica}

El diagnóstico participativo requiere de dos partes. La primera fase de análisis se enfoca en el estudio del contexto del problema, teniendo en cuenta las características de la población, los actores y factores implicados en el problema, y a su vez los aspectos históricos y contextuales para comprender cuales son las características generales de la población y el entorno que se está trabajando.

Desde la teoría de las redes sociales se presentan los actores sociales como los grupos que influyen de manera activa en la construcción de las subjetividades de las personas. Estos son los espacios donde se dan gran parte de las relaciones sociales. Las relaciones son analizadas mediante los vínculos entre organizaciones y se representa de manera gráfica como lazos relacionales que se dan entre un conjunto de organizaciones sobre determinado espacio físico/geográfico. Las relaciones directas entre dos organizaciones se presentan como una diada o una triada y en donde también se forman subgrupos con relaciones indirectas según las variables de análisis.

El análisis de las redes sociales se realiza en la segunda fase de la consulta mediante el estudio de redes de los grupos y organizaciones que son parte de la construcción de las representaciones sociales que pueden intervenir en el mejoramiento, la promoción de programas y actividades en los parques públicos. Esto se consulta vía telefónica o presencial con un instrumento de matriz sociométrica a partir de una entrevista semiestructurada para conocer cuáles son los programas y proyectos que ofrecen y

$3 \quad$ Mapeo de infraestructura para recreación y deporte realizado en el TCU-611(2015) por Natalia Caro Bernal y Alberto Durán. sobre los vínculos que tiene con otras instancias gestoras. Esta información se analiza con el software de UCINET para aplicar la técnica de sociogramas que permitan visualizar gráficamente cuales son los vínculos y relaciones institucionales existentes y reflexionar sobre cómo se pueden coordinar para una efectiva gestión y planificación en los parques públicos de Tibás. 
Los resultados del análisis de redes se recaudaron mediante entrevistas semiestructuradas a organizaciones y grupos comunales alrededor del tema de investigación. Con las preguntas de la entrevista semiestructurada, se obtuvieron los resultados de los grupos, grafos y tabla del cantón de Tibás.

\section{Fuentes de información:}

Las instituciones se estudian mediante el contacto directo con 11 representantes de los grupos del mapeo de programas y proyectos 2015 realizado en el TCU-611, donde se encuentran los números y direcciones de estos lugares. También se contó con la participación de las organizaciones que informen a las personas de la comunidad mediante una entrevista semiestructurada para el análisis de la matriz relacional a nivel cantonal. Las fuentes de información con las que se cuenta son:

Análisis de Situación de Salud (ASIS) de la clínica Clorito Picado (2017), clínica Rodrigo Fournier y el Ebais de León XIII sobre datos sociodemográficos de cada distrito, Censo Poblacional 2011 del INEC y Proyecciones poblacionales 2017del INEC sobre el cantón de Tibás.

Diagnóstico participativo con enfoque de derechos: un acercamiento a la realidad de los derechos de la niñez y adolescencia en el cantón de Tibás hecho por el PANI en el 2014.

Mapeo de programas y proyectos TCU-611 UCR-PANI durante el 2015 para tener los contactos, números y direcciones de lugares que brindan actividades culturales, artísticas y recreativas.

- Mapeo de espacios públicos de Tibás TCU-611 UCR-PANI durante el 2015 para conocer el estado de infraestructura de los parques, con cuales recursos se cuentan y cuales faltan en dichos espacios.

- Marco legal y normativo a partir de las leyes del Ministerio de Vivienda y Asentamientos Urbanos, Código de la Niñez y Adolescencia, Ley de Planificación Urbana y Plan Regulador de Tibás.

- Análisis de redes sobre la planificación de proyectos en parques públicos de las 11 instituciones interesadas en participar en el proyecto.

- Sistematización y retroalimentación de los talleres institucionales sobre el análisis de redes.

\section{Resultados Análisis de redes sociales en el cantón de Tibás.}

\section{Análisis de redes}

Con la fundamentación teórica del análisis de redes, se realizó un estudio con la técnica de sociometría como ciencia que mide las relaciones interpersonales, las cuales fueron recolectadas con la entrevista semiestructurada a las instituciones participantes con respecto a la gestión de actividades y proyectos en parques públicos y conforme al grado de vinculación que tienen con otras instituciones. La sociometría, como el análisis matemático de las relaciones entre instituciones con respecto al tema de investigación, permite visualizar la proximidad y distancia social que se da entre las 11 instituciones interesadas en participar en el mejoramiento de parques públicos del cantón Tibás.

Los resultados del análisis de redes se recolectaron mediante entrevistas semiestructuradas a organizaciones y grupos comunales alrededor del tema de investigación Con las preguntas de la entrevista semiestructurada, se obtuvieron los resultados de las instituciones que realizan actividades sobre arte, cultura, recreación y educación en parques públicos de Tibás y que se presentaron en el taller institucional realizado el viernes 27 de julio del 2018. Este contó con la participación de una persona en representación de cada institución: Unión Cantonal de Asociación de Desarrollo, el Concejo Municipal, la Municipalidad, delegada de la supervisora de distrito sector 4 del Ministerio de Educación, Ministerio de Salud, Clínica Coopesain, Clínica Clorito Picado y la Fuerza Pública. 
Figura 5. Grupo 1. Instituciones que ofrecen actividades y proyectos artísticos en parques públicos de Tibás. San José, Costa Rica, 2018 Fuente: Elaboración propia a partir de datos recolectados en entrevistas semiestructuradas de instituciones en Tibás.

Figura 6. Grupo 2. Instituciones que ofrecen actividades y proyectos culturales en parques públicos de Tibás. San José, Costa Rica, 2018 Fuente: Elaboración propia a partir de datos recolectados en entrevistas semiestructuradas de instituciones en Tibás.
Figura 7. Grupo 3. Instituciones que ofrecen actividades y proyectos educativas en parques públicos de Tibás. San José, Costa Rica, 2018. Fuente: Elaboración propia a partir de datos recolectados a entrevistas semiestructuradas de instituciones en Tibás.

Figura 8. Grupo 4. Instituciones que ofrecen actividades y proyectos recreativos en parques públicos de Tibás. San José, Costa Rica, 2018. Fuente: Elaboración propia a partir de datos recolectados a entrevistas semiestructuradas de instituciones en Tibás.

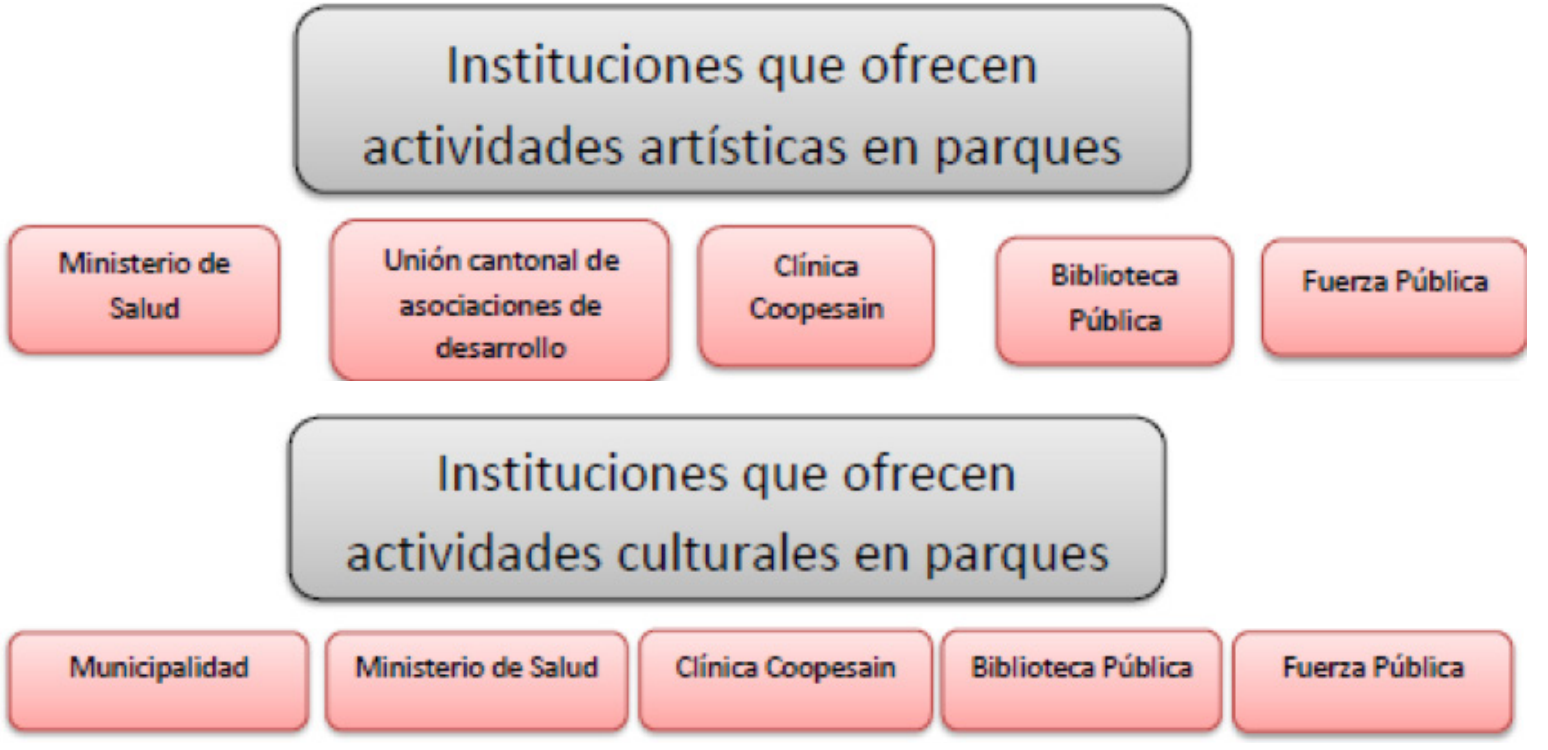

Las actividades artísticas y culturales que ofrecen las 11 instituciones del cantón se complementan con el esfuerzo de diferentes redes como la Red de No Violencia, la Red Costarricense de Actividad Física (RCAFIS) y Red del Adulto Mayor, que permiten facilitar los vínculos entre instituciones que se encargan de la planificación de actividades y proyectos para las diferentes poblaciones del cantón, lo cual ha sido un gran esfuerzo a nivel del cantón por unir las competencias de cada grupo y lograr objetivos en común.

La Municipalidad de Tibás, el Ministerio de Salud y la Fuerza Pública se encuentran anuentes a recibir propuestas de proyectos y actividades en espacios públicos que promuevan la recuperación y la participación de las personas en los parques públicos, fomentando así la apropiación comunal de los lugares y disminuyendo las problemáticas sociales como la inseguridad, drogadicción, alcoholismo, entre otras, que se presencian en los espacios públicos.
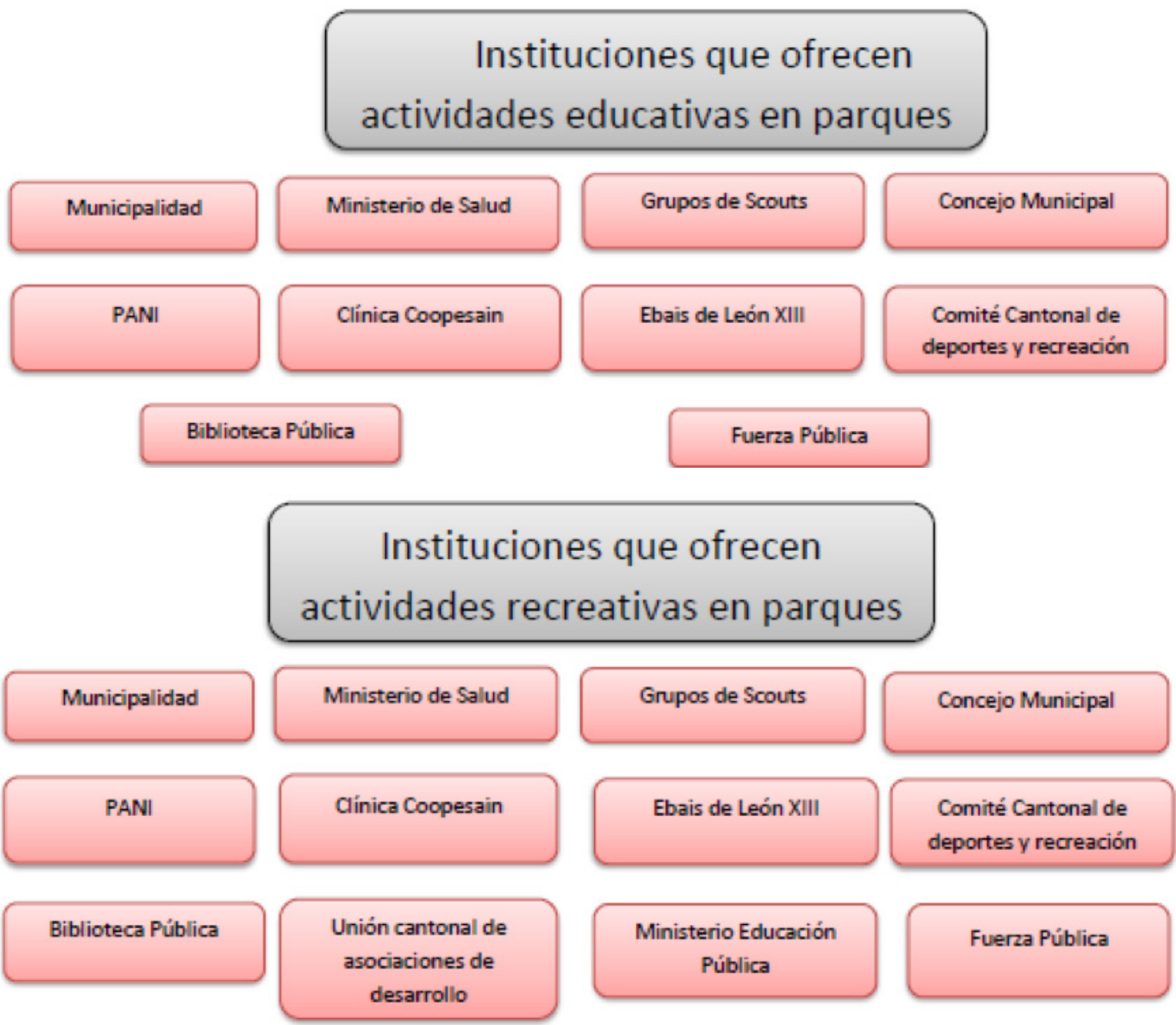

Estos grupos permiten visualizar la cantidad de actividades y proyectos que planifican diferentes instituciones en el cantón de Tibás. Al ser presentadas en el taller institucional, se permitió que conozcan los aportes de otras instituciones y coordinen nuevos proyectos en conjunto para tener una mayor participación e incidencia a nivel comunal, según las líneas de estrategias de acción formuladas por cada sector.

Durante la entrevista semiestructurada, se consultó a las personas representantes de las instituciones sobre cuáles son las relaciones que tienen con otros grupos a la hora de planificar proyectos y actividades artísticas, culturales, educativas y recreativas en parques públicos. Esto se procesó bajo una matriz sociométrica para indicar los grados de vinculación que tienen los diferentes grupos consultados entre sí. Inicialmente se 
Figura 9. Relaciones existentes entre instituciones para realizar la convocatoria actividades y programas que ofrecen en parques públicos de Tibás. San José, Costa Rica, 2018. Fuente: Elaboración propia a partir de datos recolectados en entrevistas semiestructuradas a instituciones formales del cantón de Tibás.

Relaciones recíprocas: Azul

Relaciones no recóprocas: Rojo
Figura 10. Relaciones existentes entre instituciones para ejecutar actividades y programas que ofrecen en parques públicos de Tibás. San José, Costa Rica, 2018. Fuente: Elaboración propia a partir de datos recolectados en entrevistas semiestructuradas a instituciones formales del cantón de Tibás. Relaciones recíprocas: Azul

Relaciones no recóprocas: Rojo consulta con cuales organizaciones se contactan para realizar la convocatoria a las actividades que ofrecen. Se presenta el desarrollo del análisis de redes sociales con la Figura 9.

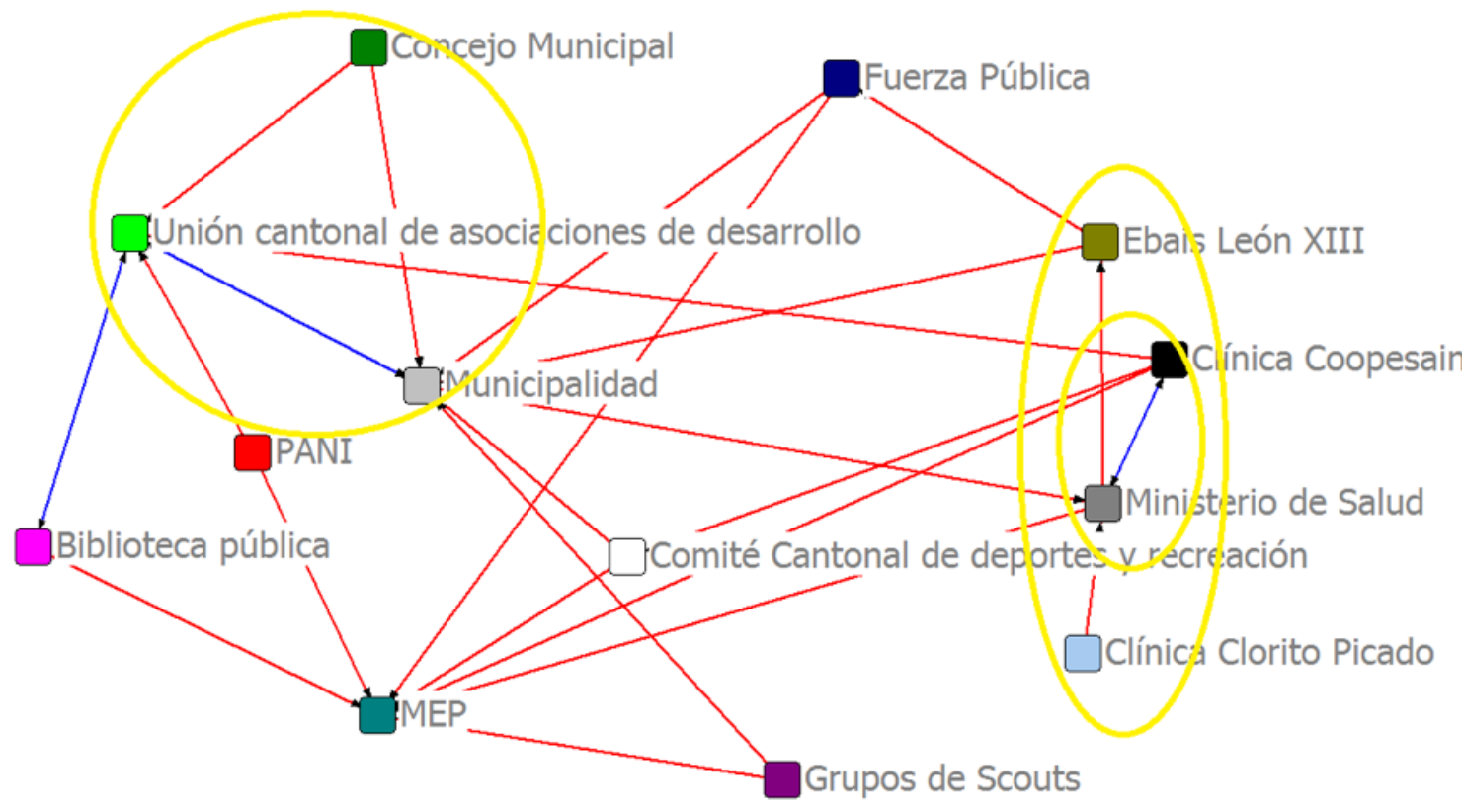

A partir del análisis teórico de las redes sociales, se pueden visualizar las relaciones que tienen los diferentes actores sociales a la hora de realizar la convocatoria de las diferentes actividades que ofrecen. Anteriormente, se explicó que la sociometría se define como el análisis matemático de las relaciones entre actores sociales sobre determinado tema. En esta figura se visualiza la proximidad y distancia social que tienen las instituciones a la hora de realizar la convocatoria.

Al realizar el análisis de centralidad, se visualizan dos subgrupos con relaciones indirectas: 1. Unión Cantonal de Asociaciones de Desarrollo, la Municipalidad y el Concejo Municipal; 2. El Ministerio de Salud y las clínicas. Se visualizan a los Scouts como un actor aparte que solo coordina con la municipalidad y los centros educativos. Se visualiza una diada entre el Ministerio de Salud y la Clínica Coopesain, ambas instituciones han trabajado constantemente para realizar actividades en espacios públicos que mejoren la calidad de vida de las personas en el cantón.

La tercera consulta realizada en la entrevista se basa en conocer las relaciones existentes a la hora de ejecutar actividades y proyectos en parques públicos de Tibás:

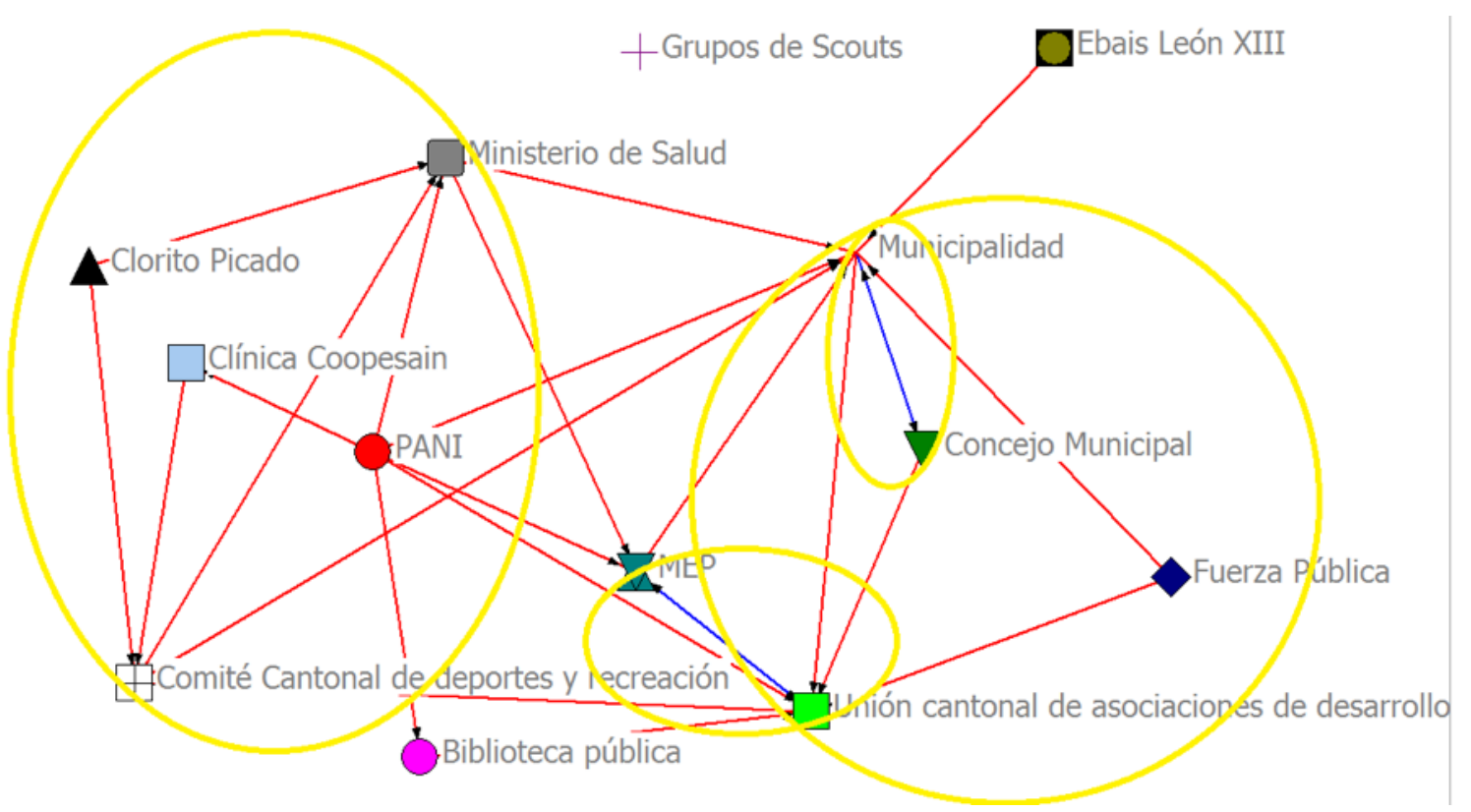

En la Figura 10 se visualizan las relaciones existentes a nivel comunal para ejecutar las actividades. Se forman dos subgrupos: 1. Ministerio de Salud con las tres clínicas, el PANI y el Comité Cantonal de Deportes; 2. Unión Cantonal de Asociaciones de Desarrollo, Fuerza Pública, el Concejo Municipal y la Municipalidad. Se forma una diada entre la Municipalidad y el Concejo Municipal. Se visualiza que el grupo de Scouts se encuentra aparte en esta red de relaciones, lo cual es un factor importante de tener en cuenta, ya que es un grupo en el cual participan muchos jóvenes del cantón que requiere espacios adecuados para la recreación y deporte.

Porúltimo, se presentan las relaciones existentesanivel comunal entre las organizaciones consultadas con respecto a la gestión de actividades en parques públicos. 
Figura 11. Relaciones existentes a nivel comunal entre las organizaciones con respecto a la gestión de actividades y proyectos en públicos de Tibás.

Fuente: Elaboración propia a partir de datos recolectados en entrevistas semiestructuradas a instituciones formales del cantón de Tibás.

Relaciones reciprocas: Azul

Relaciones no recóprocas: Rojo
Tabla 1. Tabla de las instituciones y las relaciones con otros grupos existentes según las medidas de centralidad sobre la planificación de actividades en parques públicos de Tibás, San José, Costa Rica, 2018

Fuente: Elaboración propia según matriz de relaciones procesada con el software UCINET con el análisis de las mediadas de centralidad.

$4 \quad$ Sistema operativo para el análisis de redes sociales que define las medidas de centralidad en cuanto a las relaciones y vínculos entre personas, grupos o instituciones Ver https:// www.scientec.com.mx/ucinet/

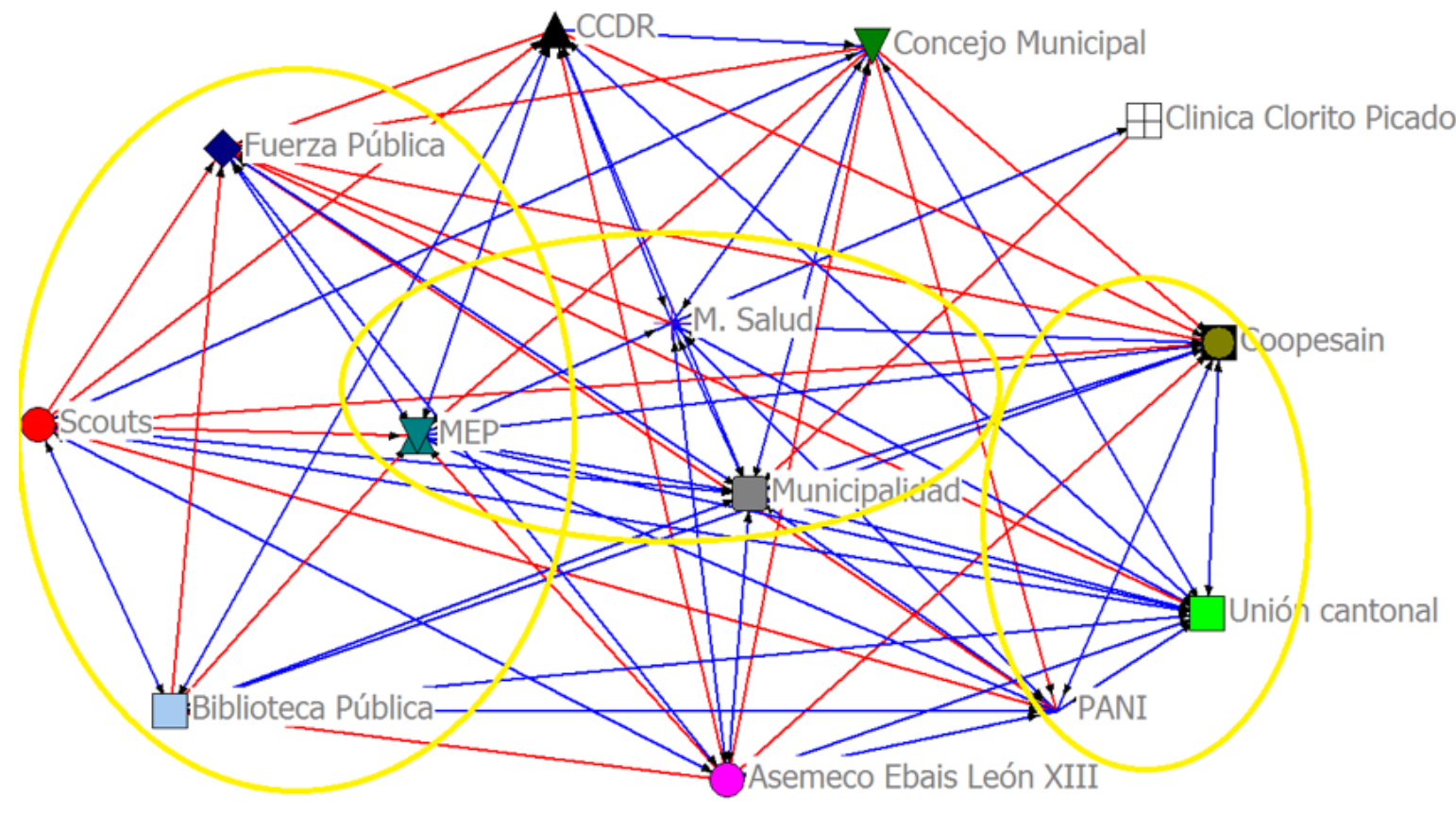

El análisis de la figura anterior permite visualizar una determinada estructura de relaciones definida como estrella, ya que tiene organizaciones centrales que se agrupan como una triada, en este caso la Municipalidad de Tibás, el Ministerio de Educación y el Ministerio de Salud, con la cual la mayoría de las demás instituciones tienen una relación recíproca y directa para planificar actividades en parques públicos. Las relaciones entre los demás grupos son variadas. Se puede visualizar una triada entre Coopesain, el PANI y la Unión Cantonal de Asociaciones de Desarrollo y un subgrupo entre los Scouts, la biblioteca, la Fuerza Pública y el Ministerio de Educación.

El análisis de centralidad permite analizar los grados de relación existente que tiene cada organización mediante el procesamiento de los datos con el software Ucinet ${ }^{4}$ que indica el número de relaciones, la cantidad de referencias de planificación, las medidas entre relaciones y las medidas de centralidad para cada una de las instituciones consultadas, las cuales se presentan en el siguiente grupo:

\begin{tabular}{lllll}
\hline Institución & Número de relaciones & Referencia para & Medidas entre & Centralidad entre \\
& con otras instituciones & planificación con otras \\
instituciones & relaciones (entre más & instituciones (entre \\
& & alto, mayor número & más cerca al número \\
& & & & \\
& & & tiene más relaciones) menor cantidad de \\
& & & relaciones coinciden \\
& & & entre instituciones)
\end{tabular}

\begin{tabular}{|c|c|c|c|c|}
\hline Municipalidad & 11 & 12 & 14.81 & 14.81 \\
\hline $\begin{array}{l}\text { Ministerio de } \\
\text { salud }\end{array}$ & 10 & 9 & 17.16 & 14.16 \\
\hline Grupos scouts & & 5 & 0.78 & 0.78 \\
\hline $\begin{array}{l}\text { Consejo } \\
\text { Municipal }\end{array}$ & 10 & 6 & 0.89 & 0.76 \\
\hline PANI & 9 & 9 & 1.88 & 1.59 \\
\hline $\begin{array}{l}\text { Unión } \\
\text { cantonal de } \\
\text { asociaciones } \\
\text { de desarrollo }\end{array}$ & 11 & 10 & 5.31 & 5.01 \\
\hline Ebais León XIII & & 6 & 4.83 & 4.37 \\
\hline $\begin{array}{l}\text { Clínica Clorito } 2 \\
\text { Picado }\end{array}$ & 2 & 1 & 0.00 & 0.00 \\
\hline $\begin{array}{l}\text { Clínica } \\
\text { Coopesain }\end{array}$ & 7 & 10 & 1.26 & 0.96 \\
\hline $\begin{array}{l}\text { Biblioteca } \\
\text { pública }\end{array}$ & 8 & 7 & 1.34 & 1.34 \\
\hline $\begin{array}{l}\text { Comité } \\
\text { Cantonal de } \\
\text { deportes y } \\
\text { recreación }\end{array}$ & 8 & 8 & 1.61 & 1.32 \\
\hline MEP & 7 & 11 & 3.09 & 2.47 \\
\hline Fuerza pública 3 & & 11 & 1.01 & 1.01 \\
\hline
\end{tabular}




\section{Conclusiones del análisis de las relaciones institucionales.}

Interpretaciones de las medidas de centralidad

La Municipalidad de Tibás tiene relación con 11 de las 13 instituciones a nivel comunal, lo cual indica el interés que tiene el gobierno local por realizar mejoras a nivel comunal en espacios públicos mediante diferentes proyectos que involucren a varias organizaciones del cantón. Por lo tanto, presenta una medida de relaciones alta de 14,81 y entre las más altas de medidas de centralidad con 14,18, lo cual demuestra que la municipalidad tiene la capacidad de ser el ente coordinador para realizar actividades y programas en estos espacios.

El Ministerio de Salud tiene relación con 10 de las 13 instituciones consultadas mediante diferentes redes en las que participan como la Red de No Violencia a partir del decreto Ejecutivo No. 26664 del 27 de enero de 1998 y RCAFIS a partir del decreto 32886 del 16 de febrero de 2006 donde se indican las leyes sobre las acciones que deben tomar las instituciones participantes para beneficio de las comunidades. La Clínica Coopesain tiene relación directa con 7 instituciones, ya que es parte de la red RCAFIS. La Clorito Picado solo tiene relación con 2 instituciones, lo cual permite visualizar la importancia de que esta institución participe de manera activa en la planificación del cantón. Se anexa el decreto de la conformación de la red.

Los grupos de Scouts tienen relación con 10 instituciones para planificar y apoyar actividades y proyectos que involucren a jóvenes de las comunidades, mayoritariamente de los distritos de San Juan, Anselmo Llorente y Colima. Sin embargo, solo 5 instituciones consideraron que tienen relaciones con los Scouts, lo que demuestra la falta de coordinación con este grupo. El Concejo Municipal tiene relación con 10 instituciones, lo que se ve reflejado en la tabla como la medida de relaciones de 0,89 , lo cual es un aspecto relevante a mejorar para tener una incidencia directa en proyectos que mejoren la calidad de vida de las personas en cada uno de los cinco distritos.

EI PANI tiene relación con 9 instituciones, ya que participa en diferentes redes como RCAFIS y coordina el Subsistema Local de Niñez y Adolescencia en donde participan diferentes representantes de instituciones para coordinar proyectos para personas menores de edad. La biblioteca tiene relación con diferentes instituciones por el préstamo de servicios educativos para redes interinstitucionales. La Unión Cantonal de Asociaciones de Desarrollo tiene relación con todas las instituciones a nivel comunal, ya que las asociaciones de desarrollo de cada distrito se han organizado con diferentes iniciativas que benefician al cantón de Tibás. Sin embargo, la Unión Cantonal tiene un 5,31 en medidas de relaciones, lo cual si se fortalece, lograría que los proyectos y actividades que ofrecen tengan una mayor incidencia en el cantón.

El Ebais de la León XIII tiene relación con 11 instituciones (4,83 medida de relación), estas relaciones se dan por la participación del Ebais en la Junta de Salud de León XIII, mesas de diálogo comunales y juntas del adulto mayor donde se han consolidado diferentes proyectos en beneficio del distrito.

El Comité Cantonal de Deportes tiene relación con 8 instituciones, pero actualmente

Figura 12. Foto tomada en el taller institucional del 27 de julio del 2018.

Fuente: elaboración propia

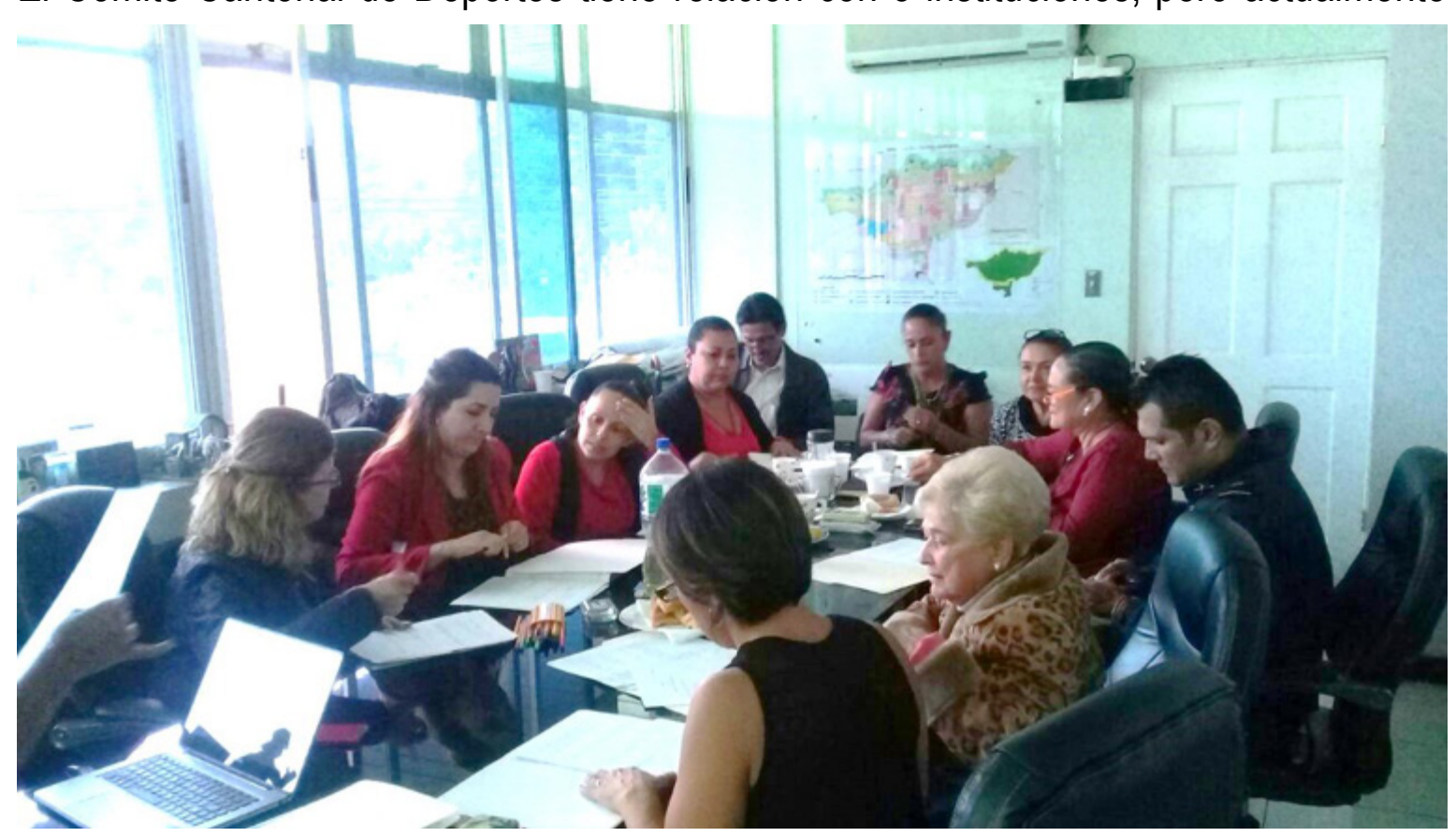


Figura 13. Foto tomada taller institucional del 27 de julio del 2018.

Fuente: elaboración propia ha tenido algunas situaciones organizativas que no han permito consolidar a los representantes. Sin embargo, están tomando las medidas para coordinarlo. El Ministerio de Educación tiene relación con 7 instituciones, sin embargo, la medida de relaciones es de 3,09, lo que permite inducir que el ministerio está realizando muchos esfuerzos por sí mismo y requiere del apoyo de otras instituciones para beneficio del cantón. Por último, la Fuerza Pública solo tiene relaciones con 3 instituciones a pesar de que 11 la consideran como referente para la planificación de actividades. Los y las oficiales no están recibiendo el apoyo necesario por parte de las demás instituciones para poder cumplir con sus labores.

A continuación, se presentan las líneas estratégicas de acción y los sociogramas presentados por sector de manera grupal por representantes de diferentes grupos en el taller de instituciones sociales, para la planificación de actividades en parques públicos de Tibás.

\section{Sector de Salud}

1. Apropiación de espacios por parte de la organización comunal.

2. Diversificar alternativas de desarrollo cultural, recreativo y deportivo con enfoque de género y accesibilidad.

3. Asignar recursos según necesidades y oportunidades de los diferentes distritos con equidad.

\section{Sector de Educación}

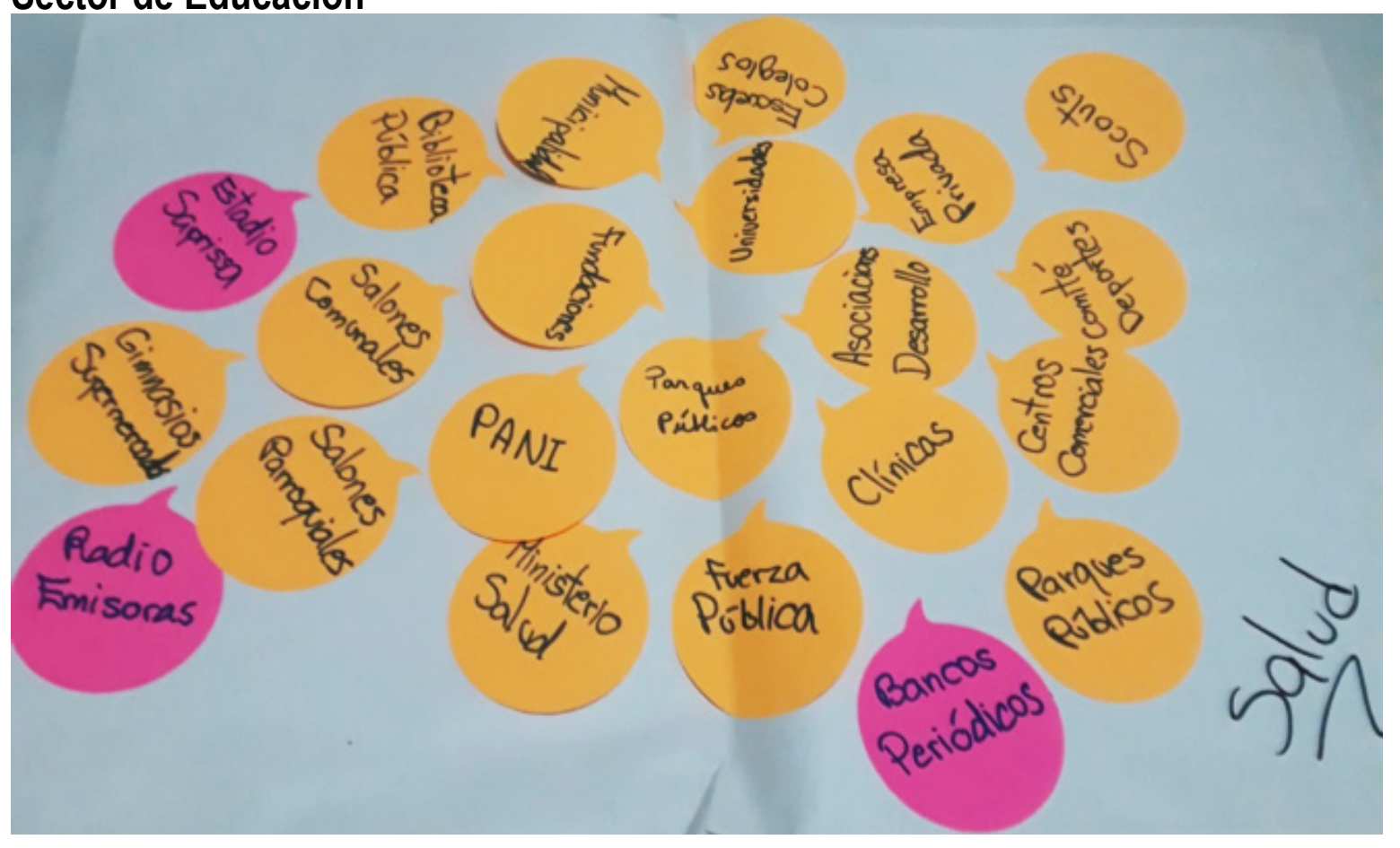

1. Tomar medidas para mejorar la seguridad y la iluminación en los parques públicos.

2. Parques inclusivos con actividades para personas con discapacidad, niñez y adolescencia.

3. Diseño de parques con autogestión que tengan un alto nivel de apropiación comunal.

\section{Sector comunal}

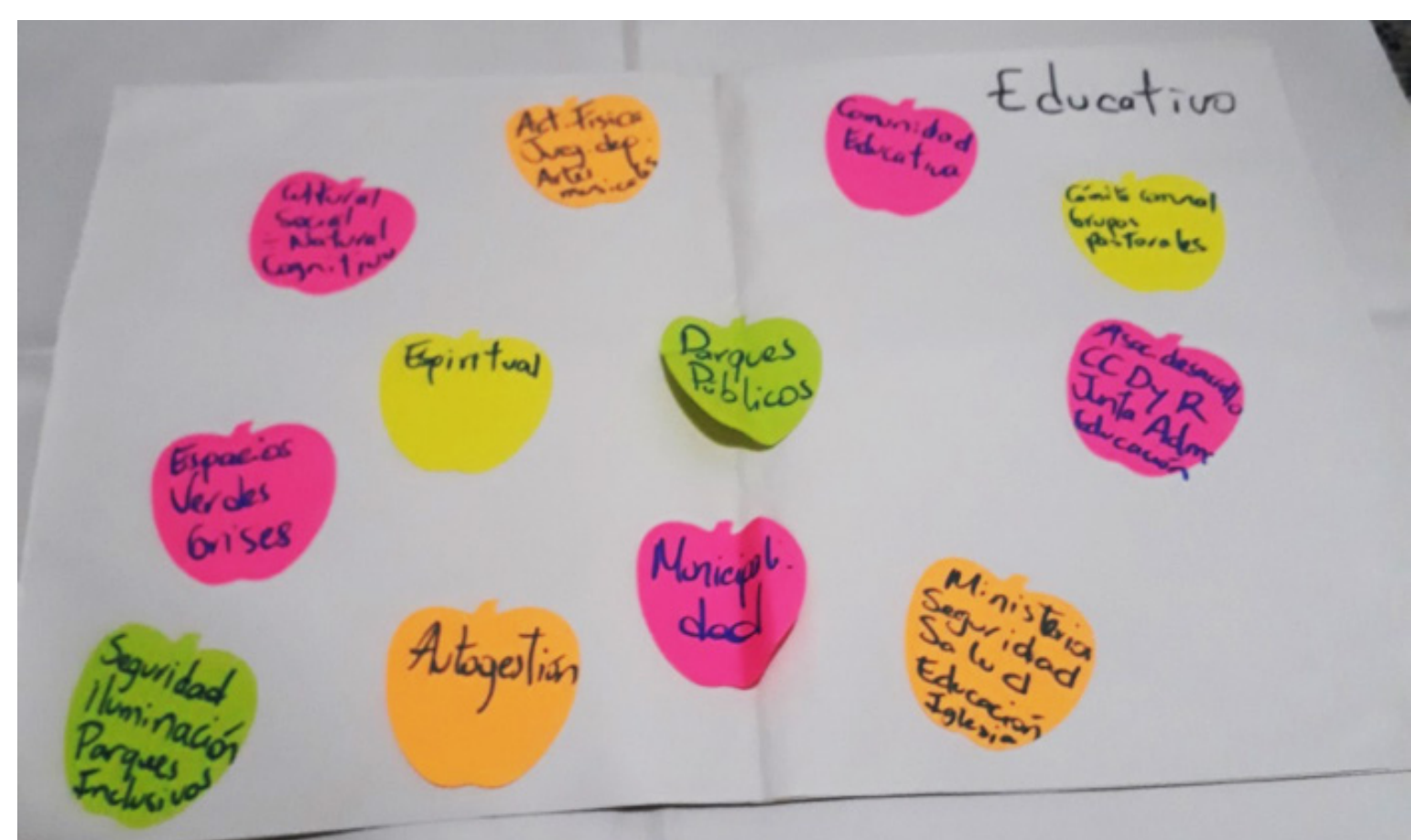


Figura 15. Foto tomada taller institucional del 27 de julio del 2018.

Fuente: elaboración propia
1. Recuperación efectiva de parques públicos.

2. Motivación de participación con fuerza pública de las distintas comunidades.

3. Alianza y cooperación con fuerza pública para utilizar estas zonas.

\section{Sector municipal}

1. Apertura de herramientas para la comunidad con el propósito de que exista una participación democrática en toma de decisiones en favor del cantón con respecto a sus parques.

2. Trabajo en proyectos comunes en red para recuperar zonas verdes.

3. Participación activa y propuestas orientadas al desarrollo de sus parques para promover el empoderamiento civil.

\section{Recomendaciones}

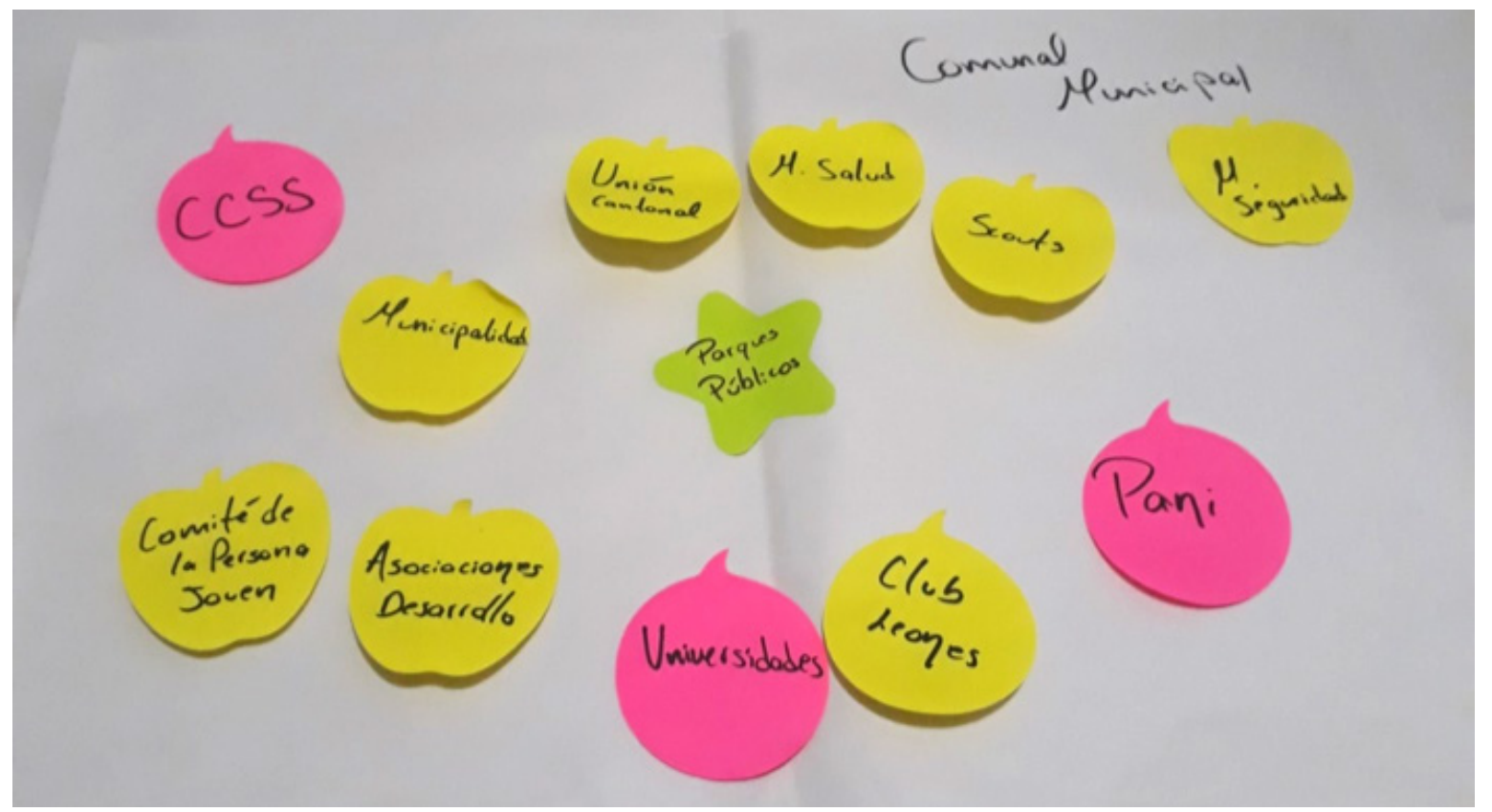

Las líneas estratégicas de acción fueron definidas en el taller institucional, en el cual las personas representantes intercambiaron sus contactos para seguir realizando programas y proyectos en conjunto e invitaron a las instituciones que no participan en RCAFIS a sumarse a esta red coordinada por el Ministerio de Salud, que busca promover la actividad física para una vida más saludable.

Estas líneas estratégicas también fueron presentadas en los talleres comunales del proyecto de graduación. Esto con el objetivo de formular los diseños de intervención mediante mapas para la recuperación de parques públicos de Tibás e incidir en el plan regulador 2016-2020. Al mismo tiempo, que el proyecto permita visualizar la importancia de una política pública a nivel nacional que involucre la participación ciudadana y el trabajo en redes para la planificación de actividades y proyectos en espacios públicos. Es necesario involucrar más a los grupos y colectivos de Tibás como los Scouts, academias de baile y deportivas, comité de la persona joven, entre otros. Al final del documento, se anexan las actividades y programas que ofrecen cada una de las instituciones para el conocimiento de las personas interesadas.

Se recomienda a las personas interesadas en los resultados de este artículo consultar los objetivos de desarrollo sostenible de la Organización de las Naciones Unidas, la Agenda 2030 y los lineamientos de Instituto Costarricense de Recreación (ICODER), al igual que la próxima política pública de recreación y deporte que será publicada en el 2018. Entre los Objetivos de Desarrollo Sostenible (ODS), principalmente se recomienda retomar los objetivo 3 (salud y bienestar), 4 (educación de calidad), 5 (igualdad de género), 7 (energía asequible y no contaminante), 11 (ciudades y comunidades sostenibles), 13 (acción por el clima), 15 (vida de ecosistemas terrestres), 16 (paz, justicia e instituciones sólidas) y 17 (alianzas para lograr los objetivos). Estos cuentan con indicadores específicos que, al ser incluidos dentro del plan regulador de Tibás y su ejecución, lograrán mejorar la calidad de vida de las personas.

El Instituto Costarricense del Deporte y la Recreación (ICODER) tiene como misión 
Figura 16. Foto tomada en el taller institucional del 27 de julio del 2018.

Fuente: elaboración propia

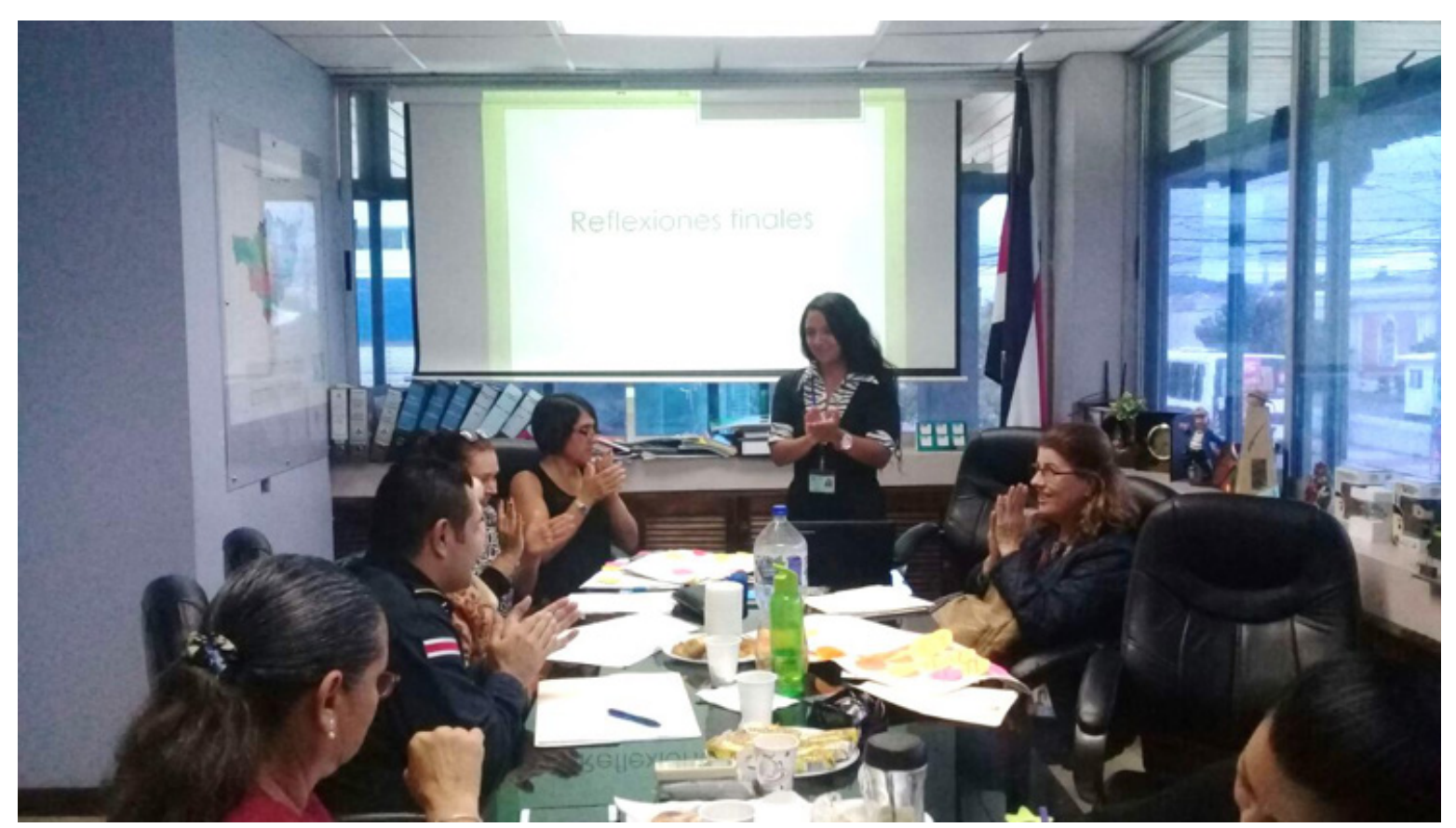

"promover el deporte, la recreación y la actividad física, con el fin de contribuir al desarrollo y bienestar integral de la población de la república" (ICODER, s.f). La visión del mismo es "ser la institución líder en el deporte, la recreación y la actividad física a nivel nacional y un referente en el ámbito internacional" (ICODER, s.f). Esta institución está diseñando la política pública de recreación y deporte, la cual va a ser una excelente herramienta para hacer valer los derechos de las personas en cuanto a este tema y propiciar el mejoramiento de estos espacios públicos. También es una institución importante de tomar en cuenta para realizar alianzas a la hora de planificar actividades y proyectos en espacios públicos que fomenten la participación comunal y el involucramiento ciudadano en el cantón Tibás.

En general, la principal recomendación que se presenta en este artículo es desarrollar un modelo de gestión de involucramiento ciudadano a partir de las propuestas municipales, institucionales y comunales con el fin de que se dé una mayor participación de las personas en diferentes espacios públicos para el beneficio del cantón y la calidad de vida de las personas. Este punto es fundamental ya que con una buena coordinación entre las instituciones se puede lograr mayor divulgación, más presupuestos, horarios y lugares accesibles para que las personas de todas las edades tengan la posibilidad de participar y apropiarse de los espacios públicos.

\section{Referencias bibliográficas}

Asamblea Legislativa de Costa Rica. (1968). Ley de Planificación Urbana, San José, Costa Rica. Recuperado de: https://www.cne.go.cr/cedo_dvd5/files/flash_ contentpdf/spa/doc376/doc376-contenido.pdf

Atlas cantonal. (2009). Índice de Desarrollo humano con el índice de Seguridad Ciudadana Cantonal Costa Rica. Recuperado de: http://desarrollohumano.or.cr/ mapacantonal/atlas.pdf

Clínica Clorito Picado ASIS Tibás. (2017). Datos sociodemográficos del cantón.

Clínica Coopesain ASIS Tibá. (2017). Datos sociodemográficos del cantón.

Foro Mundial de las Américas. (2004). Carta Mundial por el Derecho a la Ciudad, Quito, Perú. Recuperado de: https://www.ugr.es/ revpaz/documentacion/rpc_ n5_2012doc1.pdf

Instituto Costarricense de Deporte y Recreación. (s.f). Misión y visión. Recuperado de http://www.icoder.go.cr/

Loria, R. (2016). Guía de diagnóstico participativo. Escuela de Antropología. Universidad de Costa Rica.

Municipalidad de Tibás. (2015-2016). Datos de parques públicos y espacios públicos en Tibás. San José, Costa Rica.

Ministerio de Vivienda y Asentamientos Urbanos. (2012). Política Nacional de Ordenamiento Territorial 2012 a 2040. San José, Costa Rica. Recuperado de: 
https://www.mivah.go.cr/Documentos/transparencia/Informes_Gestion/Inf_Ges_ Min_Irene_Campos/PNOT_2012-10-22_Aprobada.pdf

Organización de las Naciones Unidas. (2016). Objetivos del desarrollo sostenible. Recuperado de: http://www.ods.cr/

Organización de las Naciones Unidas. (2016). Agenda 2030. Recuperado de: http:// www.sela.org/media/2262361/agenda-2030-y-los-objetivos-de-desarrollosostenible.pdf

Patronato Nacional de la Infancia. (2014). Diagnóstico participativo con enfoque de derechos: un acercamiento a la realidad de los derechos de la niñez y adolescencia en el cantón de Tibás. San José, Costa Rica.

Patronato Nacional de la Infancia. (1997). Código de Niñez y Adolescencia. Recuperado de: https://pani.go.cr/descargas/codigo/456-codigo-ninez-y-adolescencia-7739/ file

Pol, E. (1996). La apropiación del espacio. Iñiguez L. y Pol, E. (comp.), Cognición, representación y apropiación del espacio. Colección Monografies psico/socio/ ambientals (9). Barcelona: Universidad de Barcelona.

Rizo, M. (2006). Conceptos para pensar lo urbano: el abordaje de la ciudad desde la identidad, el habitus y las representaciones sociales. En bifurcaciones, 6 . Recuperado de www.bifurcaciones.cl/006/Rizo.htm

Wasserman, S. \& Faust, K. (1994). Social network analysis: Methods andapplications, United States of America: Cambridge University Press.

Wellman, B. \& Berkowitz, S.D. (1991). Social Structure. ANetworkApproach. Cambridge: Cambridge University Press.

\section{Apéndice 1: Entrevista semiestructurada}

1. ¿Cuáles actividades, proyectos y programas ofrecen en temas de arte, cultura, educación y recreación?

2. ¿Con cuales dos principales instituciones se contactan para realizar la convocatoria de personas a las actividades, proyectos y programas que ofrecen?

3. ¿Con cuales dos instituciones se contactan para realizar/ejecutar actividades, proyectos y programas de arte, cultura, educación y recreación?

\section{Apéndice 2: Actividades y proyectos que ofrecen las distintas organizaciones}

Actividades y proyectos artísticos que ofrecen diferentes organizaciones en parques públicos de Tibás. San José, Costa Rica, 2018. Fuente: Elaboración propia a partir de datos recolectados en entrevistas semiestructuradas de instituciones en Tibás.

Actividades y proyectos culturales que ofrecen diferentes organizaciones en parques

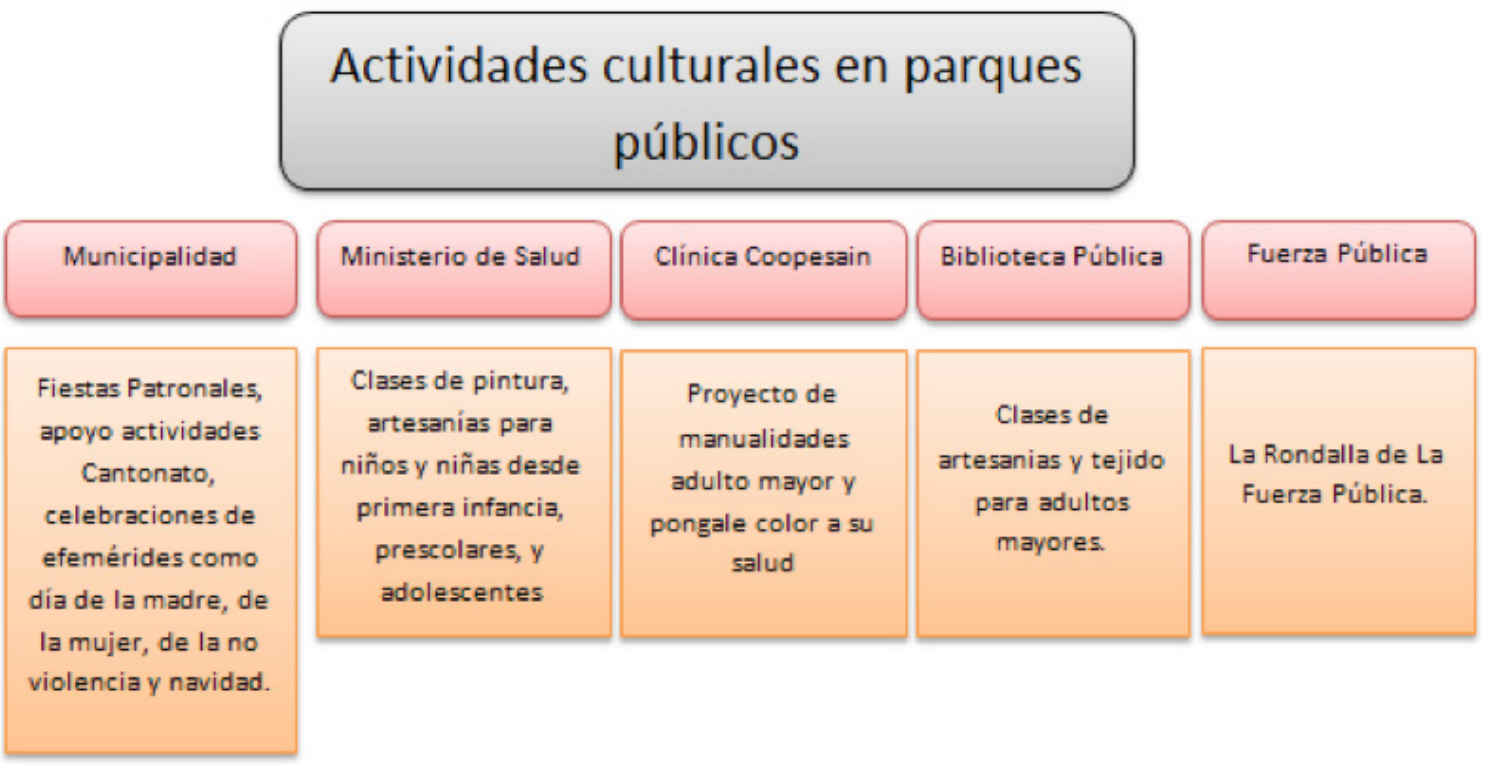


públicos de Tibás. San José, Costa Rica, 2018. Fuente: Elaboración propia a partir de datos recolectados en entrevistas semiestructuradas de instituciones en Tibás.

Actividades y proyectos educativos que ofrecen diferentes organizaciones en parques

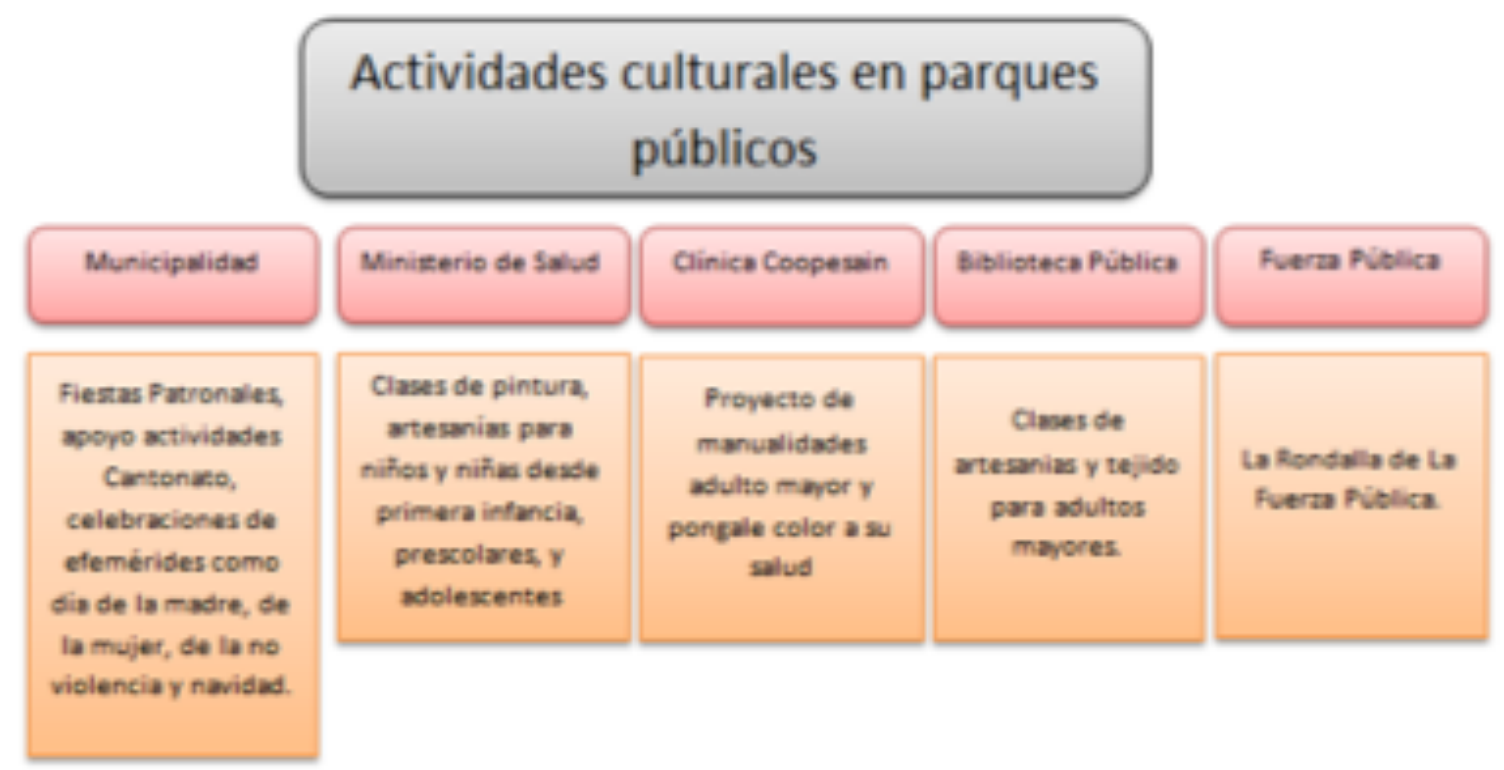

públicos de Tibás. San José, Costa Rica, 2018. Fuente: Elaboración propia a partir de datos recolectados en entrevistas semiestructuradas de instituciones en Tibás.

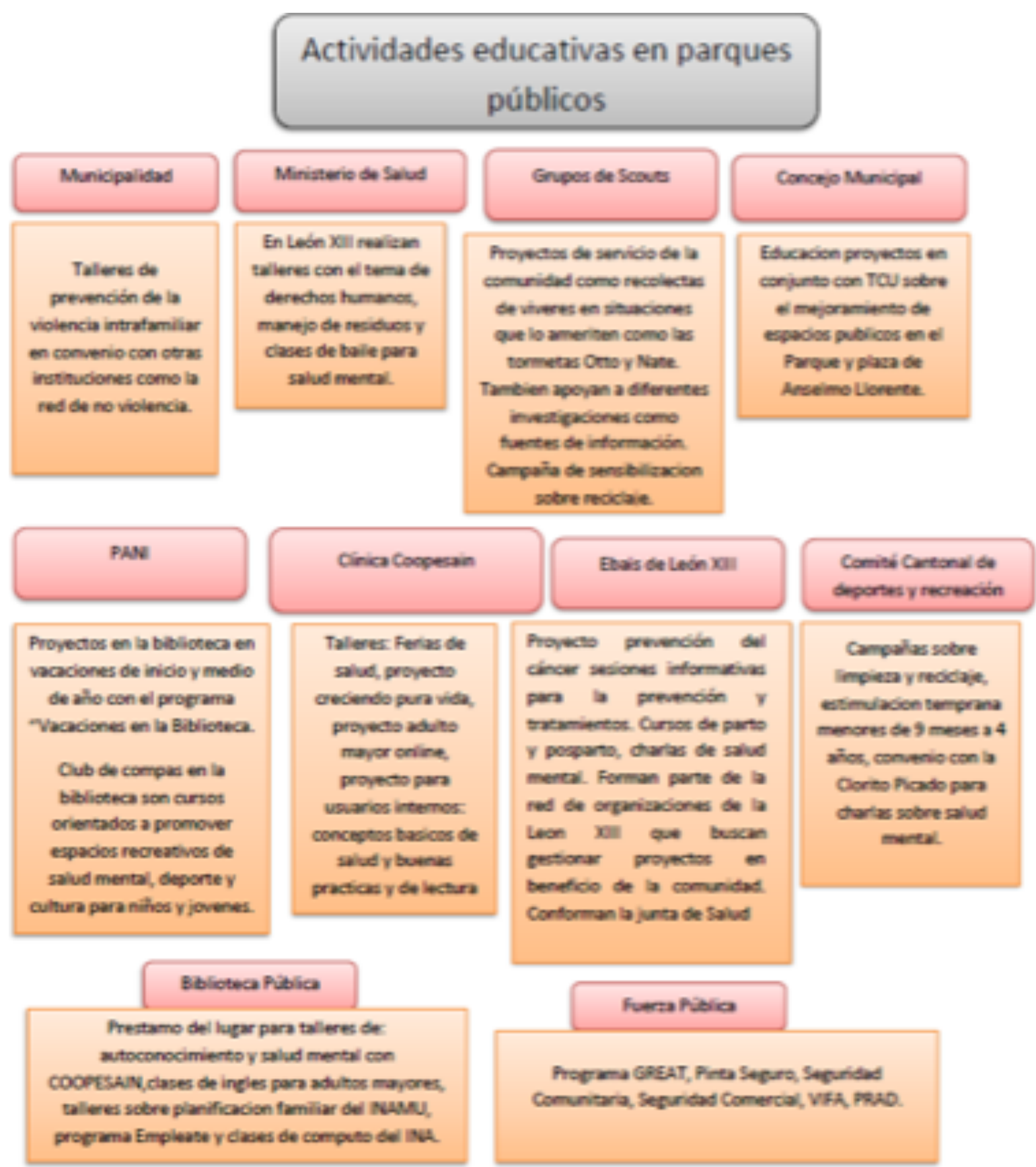

Actividades y proyectos recreativos que ofrecen diferentes organizaciones en parques 
públicos de Tibás. San José, Costa Rica, 2018. Fuente: Elaboración propia a partir de datos recolectados en entrevistas semiestructuradas de instituciones en Tibás.

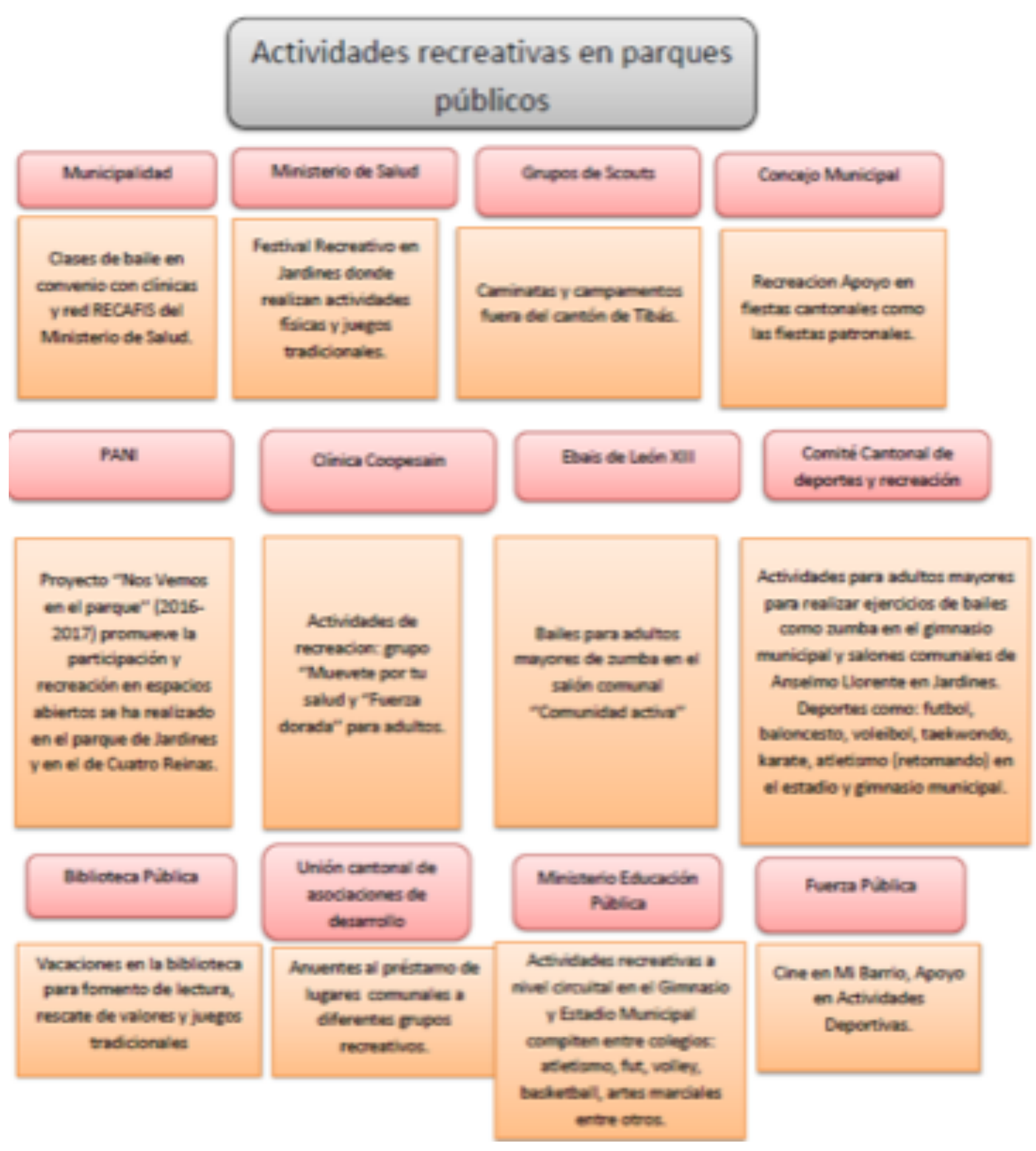

